23

\title{
Измерение поляризации света при зеркальном и диффузном отражении от растительного покрова
}

\author{
() Б.М. Азизов, Д.С. Мехтиев, С.Г. Кулиева \\ Национальная академия авиации, \\ AZ1045 Баку, Азербайджан \\ ฯe-mail: guliyeva.s.h@gmail.com \\ Поступила в редакцию 26.04.2018 г. \\ В окончательной редакции 06.02.2019 г. \\ Принята к публикации 12.02.2018 г.
}

Рассмотрены зеркальное и диффузное отражение света от листьев пшеницы на двух вегетационных этапах ее развития. Результаты исследования могут служить методологической основой для разработки моделей оптических свойств и других сельскохозяйственных культур.

DOI: $10.21883 /$ OS.2019.06.47781.113-18

\section{Введение}

Солнечное излучение, зеркально отраженное от любой растительной культуры, часто бывает настолько ярким, что при наблюдении из космоса кажется белым. В отличие от света, диффузно отраженного от листьев, зеркально отраженный свет не проникает в листья и потому имеет белую окраску, поскольку не взаимодействует с их клеточными пигментами, перегородками и содержащейся в них водой. Свойства кожицы листьев меняются в зависимости от этапа развития растения, содержания в ней воды и температурного режима. Все это показывает, что зеркально отраженный от растения свет является важным источником информации о его состоянии. Такая информация необходима для мониторинга процессов развития и роста в растениеводстве и вполне может быть получена с помощью современных методов дистанционного зондирования.

Коэффициент отражения сельскохозяйственных культур фактически определяется рассеянием света листьями, которые содержат матрицу из клеток, покрытую защитным поверхностным слоем-кожицей [1]. В процессе фотосинтеза фотоны поглощаются пигментами, находящимися в этих клетках. Непоглощенный свет в центральной области листьев в основном рассеивается за счет преломления на поверхности клеточных компонентов. Электронные микроснимки листьев пшеницы показывают, что их поверхность оптически неоднородна и имеет сложную структуру [2-7].

Многослойная кожица листа нередко бывает покрыта гладкой восковой пленкой. Электронные микроснимки листа пшеницы показывают наличие нерегулярных иглообразных восковых структур, распространенных по его плоской поверхности и напоминающих множество пеньков на очищенной лесной площадке.

Можно выделить четыре типа рассеяния света на поверхности раздела между атмосферным воздухом и кожицей листа: 1) свет зеркально отражается от оптически ровных ориентированных элементов кожицы листа;
2) свет, отраженный от слоистой кожицы листа, создает не имеющие особого значения помехи; иглообразные структуры на поверхности кожицы листьев рассеивают свет в соответствии с закономерностями рассеяния 3) Релея и 4) Ми. В случае рассеяния Релея отраженный свет поляризован линейно.

Некоторые особенности информативности поляризованного света, рассеянного растительностью и почвами, изучались авторами [3,6-9]. Используя данные лабораторных исследований и данные, полученные методами дистанционного зондирования Земли, исследователи обнаружили, что степень линейной поляризации фиксируемого самолетным бортовым датчиком света, рассеянного объектом изучения, может дать дополнительную информацию для классификации особенностей данных явлений в объектах. Было также установлено, что в процессе высыхания листьев растительного покрова их поляризационные свойства усиливаются $[8,9]$.

\section{Материалы и методы}

Данные о поляризации света посевами пшеницы были получены и исследованы во втором квартале 2013 г. в Шекинском районе Азербайджанской Республики.

В исследованиях по оценке поляризованного и диффузного отражения света посева пшеницы получены более 40 спектров в видимом диапазоне волн (от 0.46 до $0.72 \mu \mathrm{m})$ с помощью спектрофотометра UNIKO-2100, который был установлен на регулируемой высоте над почвой. Анализатор поляризации света, вмонтированный во вращающуюся скобу, был прикреплен к спектрофотометру со стороны входной части. Измерения проводились при 5 азимутальных и 4 зенитных углах $(15,20$, $\left.60,65^{\circ}\right)$.

В каждом направлении наблюдения были получены по два спектра. Один из них был получен в то время, когда анализатор поляризации света ориентировался на максимальную амплитуду сигнала детектора, а другой — когда анализатор ориентировался на минимальный сигнал. 


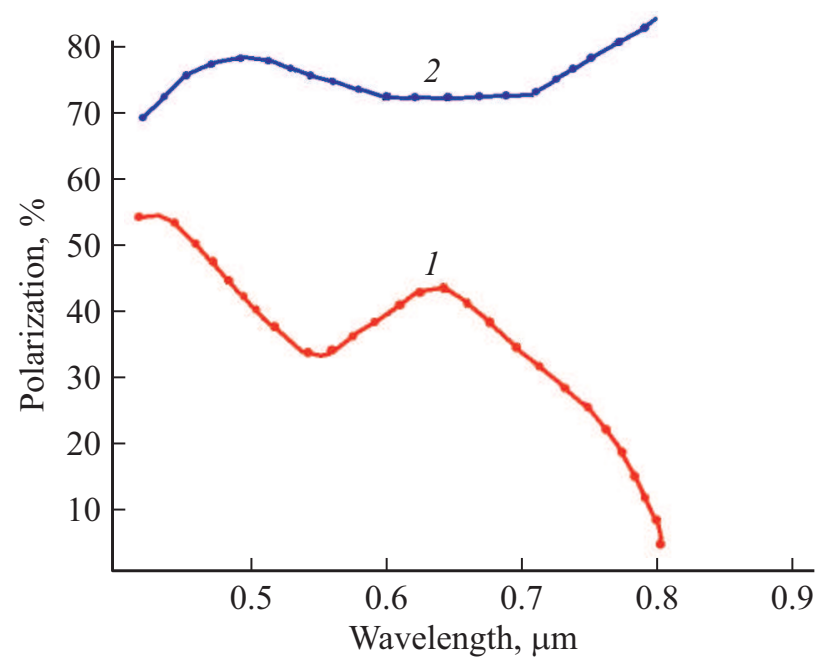

Рис. 1. Спектральная зависимость степени поляризации диффузной (1) и зеркальной (2) компонент света, отраженного от посевов пшеницы.

Анализ поляризационных свойств и свойств зеркального отражения света растительностью проводился на основе данных, полученных в 13 диапазонах, которые были выбраны с интервалами в $0.02 \mu \mathrm{m}$ в спектральной области от 0.48 до $0.72 \mu \mathrm{m}$.

Спектральное разрешение данных превосходит 1\% длины волны. Для каждой длины волны, выбранной для анализа, вычислялась степень линейной поляризации света, результаты показаны на рис. 1 .

Для каждого направления наблюдения комбинировали по два коэффициента отражения, рассчитанные по максимальной и минимальной интенсивности света, прошедшего через анализатор поляризации при различных его ориентациях, $R_{\max }$ и $R_{\min }$ (рис. 1$)$. С их помощью можно определить средний коэффициент отражения света растительностью, который соответствует коэффициенту отражения в том же направлении, измеренному без анализатора поляризации света

$$
R=\frac{R_{\max }+R_{\min }}{2}
$$

и коэффициент поляризации в определенном направлении наблюдения, соответствующий отношению линейно поляризованного излучения к излучению совершенно белой и диффузной калибровочной панели:

$$
R_{\mathrm{Q}}=\frac{R_{\max }-R_{\min }}{2} .
$$

Степень линейной поляризации, измеренная в определенном направлении, представляет собой отношение линейно поляризованного излучения к отражательной способности растительности. В зависимости от угла обзора при изменении направления отраженного от растительности излучения меняется степень поляризации.
Для пшеницы значение зеркально отраженного излучения было вычислено с помощью уравнений Френеля в предположении, что коэффициент преломления кожицы листа составляет 1.5 .

Угол падения определяется формулой

$$
\gamma=0.5 \arccos \left(\sin \theta_{\mathrm{r}} \cos \left(\phi_{\mathrm{i}}-\phi_{\mathrm{r}}\right) \sin \theta_{\mathrm{i}}+\cos \theta_{\mathrm{i}} \cos \theta_{\mathrm{r}}\right.
$$

где $\theta_{\mathrm{i}} \phi_{\mathrm{r}}-$ соответственно зенитные углы, углы по азимуту в направлении Солнца и углы наблюдения. Диффузная часть коэффициента отражения представляет собой разницу между коэффициентом отражения растительности и его зеркально отраженной частью.

\section{Результаты и обсуждение}

Выборкой из общего числа спектров $R$ и $R_{Q}$ было установлено, что значения этих показателей функционально зависят от длины волны и направления обзора. Результаты показывают, что $R$ имеет характерную для зеленой растительности форму с полосами поглощения пигментов в голубой $(<0.50 \mu \mathrm{m})$ и красной $(0.66 \mu \mathrm{m})$ областях спектра.

$\mathrm{R}$ обычно имеет самое высокое значение для данных, полученных при угле $180^{\circ}$ по азимуту, против направления Солнца, и самое низкое значение для данных, полученных при угле $0^{\circ}$ по азимуту. В отличие от $R$ спектр $R_{Q}$ не имеет формы, характерной для растительности и не содержит явных полос поглощения пигментов. Обычно $R_{Q}$ имеет самые высокие и самые низкие значения соответственно в направлениях обзора по азимуту 0 и $180^{\circ}$. Углы анализатора поляризации на радиометре, выбранные для измерения минимального и максимального излучения, были вычислены с учетом направления обзора и освещения. Минимальная энергетическая яркость измеряется тогда, когда ось анализатора находится в плоскости падения излучения. Угол между плоскостью падения излучения и местной вертикалью w, который проектируется на поле зрения радиометра, задается следующим уравнением:

$\beta=\arccos \left(\frac{\cos \theta_{\mathrm{i}} \sin \theta_{\mathrm{r}}+\cos \left(\phi_{\mathrm{i}}-\phi_{\mathrm{r}}\right) \sin \theta_{\mathrm{i}} \cos \theta_{\mathrm{r}}}{\sqrt{\sin ^{2}\left(\phi_{\mathrm{i}}-\phi_{\mathrm{r}}\right) \sin ^{2} \theta_{\mathrm{i}}+\left(\cos \theta_{\mathrm{i}} \sin \theta_{\mathrm{r}}+\cos \left(\phi_{\mathrm{i}}-\phi_{\mathrm{r}}\right) \sin \theta_{\mathrm{i}} \cos \theta_{\mathrm{r}}\right)^{2}}}\right)$.

Для зенитного угла освещения $30^{\circ}$ угол $\beta$ представляет собой функцию направления обзора, например, для направления обзора в зенитный угол $30^{\circ}$ и угол $135^{\circ}$ по азимуту от солнечного азимута, угол $\beta$ равен $40^{\circ}$. Сопоставление прогнозируемой и фактической угловой зависимости состояния поляризационного анализатора для пшеницы приведено на рис. 2. Угол падения, определенный в плоскости падения излучения, является основной переменной для понимания свойств оптического рассеяния растительности. Результаты рис. 2 служат подтверждением поляризационной модели, которая прогнозирует, что одна переменная - угол падения объясняет во многом изменение количества линейно поляризованного света в зависимости не только от углов 

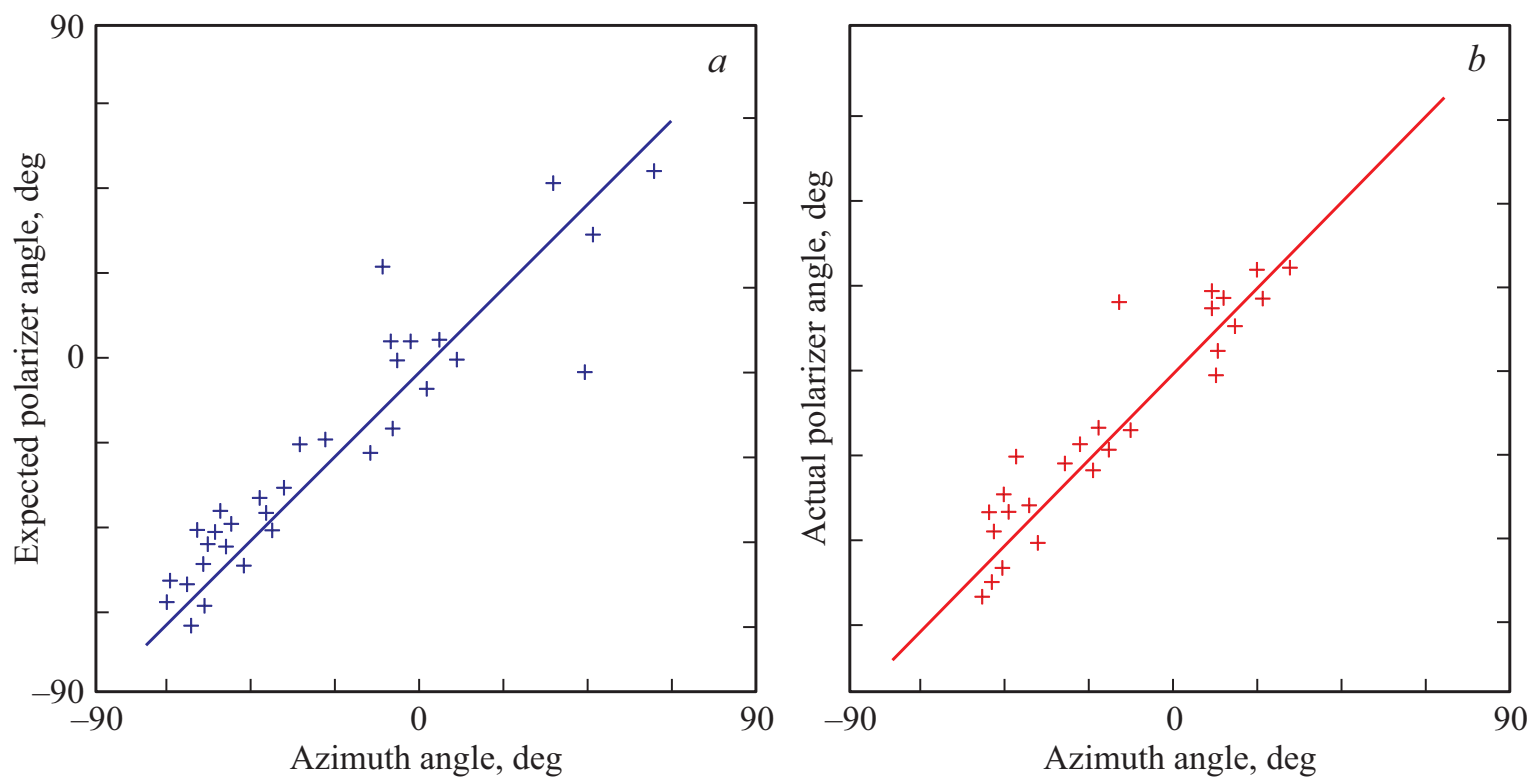

Рис. 2. Угловая зависимость прогнозируемого $(a)$ и фактического $(b)$ углов оси поляризационного анализатора для пшеницы.

обзора, но также и от углов падения солнечного излучения. Известно, что отраженное от пшеницы излучение обусловлено тремя основными источниками: в первую очередь Солнцем, а также небом и облаками. При этом угол падения излучения определяется для коллимированного излучения, такого как излучение Солнца, и не определяется для неколлимированного излучения неточечного источника, такого как голубое небо.

Если бы небесный свет или свет, исходящий от облаков, были важными поляризационными источниками излучения, то прогнозируемый угол анализатора поляризации не пояснял бы изменение в данных (рис. 2) и рассеяние в этом случае было бы намного выше.

Из четырех процессов рассеяния зеркальное отражение и релеевское рассеяние являются главными процессами, поляризующими свет, отраженный от изучаемой растительности. Если бы рассеянное релеевское излучение составляло значительную долю всего отраженного потока излучения, то тогда листовая поверхность отражала бы значительное количество голубого света и, возможно, даже имела бы заметную голубоватую окраску. Однако это не так.

В действительности, измерение коэффициента отражения при нормальном падении излучения показывает, что обычно лист пшеницы рассеивает примерно равное количество красного и голубого света и больше зеленого света, чем голубого.

На рис. 3 приводятся диффузный $R_{d}$ и зеркальный $R_{m}$ вклады в коэффициент поляризации отражения растительности для длины волны $0.66 \mu \mathrm{m}$, где зенитный угол обзора представляет собой функцию азимутального угла обзора.

В обоих случаях доля зеркального отражения минимальна в направлении солнечного азимута и максимальная в направлении азимута против направления Солн-

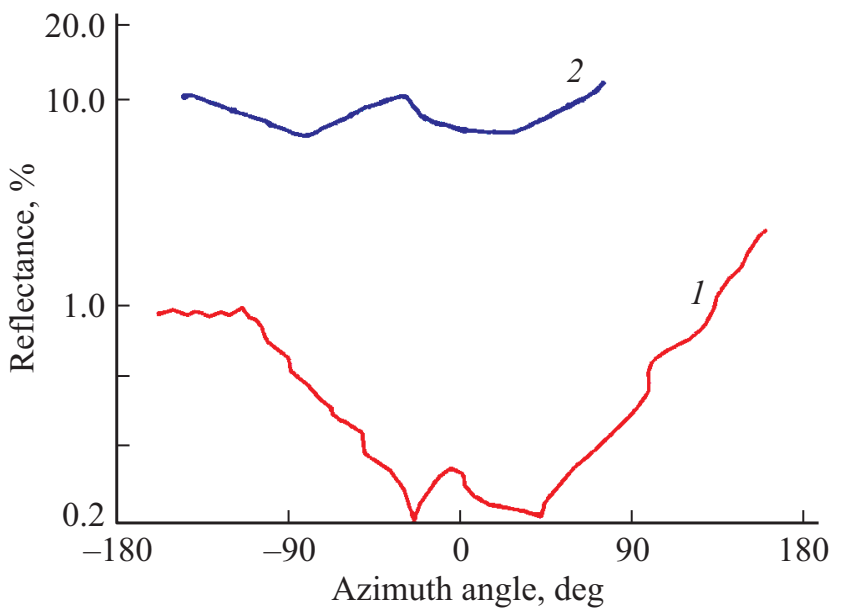

Рис. 3. Угловая зависимость коэффициента зеркального $R_{m}(1)$ и диффузного $R_{d}(2)$ отражения пшеницы.

ца. Особенно интересно понижение доли зеркального отражения по направлению к Солнцу, например, для зеркального отражения при угле обзора приближается к нулю и составляет $0.24 \%$.

Представленные на рис. 3 результаты показывают, что доля зеркального отражения обычно уменьшается при увеличении угла падения излучения (т.е. в направлении обзора в сторону солнечного азимута). Результаты проведенных визуальных наблюдений в направлении солнечного азимута показывают, что пшеница окрашена не в зеленый, а в белый цвет. Следует учитывать, что зенитный угол обзора $60^{\circ}$; если перейти к наблюдениям в направлении по солнечному азимуту при больших зенитных углах $\left(80^{\circ}\right)$, значения $R_{m}$ будут увеличиваться при увеличении угла падения излучения и направления 
наблюдений к солнечному азимуту. По-видимому, увеличение будет сильно для комбинации больших углов наблюдения в зените и больших углов падения излучения, где коэффициент зеркального отражения каждой грани может приближаться к 1.

После того, как верхушки растения пшеницы поднимаются и блокируют наблюдение зеркально отражающих излучений листьев при больших зенитных углах, по-видимому, $R_{m}$ не будет расти, а, возможно, напротив, будет снижаться при увеличении угла падения излучения. Для угла падения излучения, равного нулю (,Горячей точки“), нет затемненной лиственной поверхности - все освещено Солнцем. Наоборот, в направлении солнечного азимута затененная обратная сторона листвы занимает значительную долю поля зрения. Для углов падения, меньших, чем угол Брюстера, $R_{m}$ должен зависеть от отношения площади освещенной Солнцем поверхности листа к площади ее затемненных участков, находящихся в поле зрения, по той причине, что для растений со срезанными верхушками самые верхние листья в растении являются самым крайним сверху признаком растительности, который можно наблюдать везде. В первом приближении угловое распределение нормалей по сторонам листьев, зеркально отражающим солнечное излучение, соответствует распределению площади на сферической поверхности.

Зеркально отражающие листья видны независимо от направления наблюдения. Вероятно, чем значительнее освещена Солнцем площадь листа, оказавшаяся в поле зрения измерительного прибора, тем больше будет число сторон, зеркально отражающих солнечное излучение. В первом приближении коэффициент зеркального отражения каждой поверхности представляет собой постоянное число для углов падения, меньших $45^{\circ}$. При $n=1.5$ стабильная диэлектрическая поверхность отражает зеркально 4\% при 0 -м угле падения и $5 \%$ при $45^{\circ}$.

Понижение $R_{m}$ с увеличением угла падения излучения наблюдается как для растительности со срезанными верхушками, так и для растительности с кроной, ограничивающей угол падения излучения до $51^{\circ}$.

Таким образом, результаты, полученные по рис. 3 , соответствуют тому, что при зеркальном отражении отражательная способность растительности при углах падения, меньших, чем угол Брюстера, зависит от порции солнечного излучения к затемненным листьям в определенном направлении обзора.

Растение (пшеница) приобретает вместо зеленой белую окраску при осуществлении наблюдений при больших зенитных углах вследствие того, что меньшее количество солнечного излучения отражается зеркально от поверхности ее листьев. Наоборот, в направлении „горячей точки“ при недостатке теней и солнечного излучения, растение со способностью диффузного отражения может сократить явное значение зеркально отраженной доли коэффициента зеркального отражения. При зеркальном отражении, почти нормальном угле падения излучения („горячая точка“), листья пшеницы наблюдаются в зеленой окраске. Это происходит, вероятно, потому, что компоненты коэффициента отражения, обусловленные диффузным и зеркальным отражением, приближаются в аналогичном порядке к их величине в „Горячей точке“. Отличие наблюдается в ситуации при больших зенитных углах обзора в направлении солнечного азимута, где зеркально отраженная доля намного больше, чем доля диффузного отражения. Отметим, что погрешность проведенных измерений в зависимости от состояния растительного покрова составляла от $8 \%$ до $12 \%$.

\section{Выводы}

Поляризованная часть света, рассеянного растениями пшеницы, обусловлена солнечным излучением, зеркально отраженным от поверхностей листьев. Количество отраженного света, поляризованного при релеевском рассеянии на маленьких частицах на поверхности листьев, для этих растений незначительно. Это означает, что угол поляризации предсказуем для измерения этих зеркальных отражений от растения пшеницы в условиях ясного неба.

Коэффициент отражательной способности пшеницы можно разделить на зеркальную и диффузную компоненты. Для этих растений величина зеркально отраженного света меньше, чем для стеклянной поверхности. Все же величина зеркального отражения значительна в сравнении с величиной диффузного отражения. Следовательно, при разработке и оценке моделей взаимодействия света с растением (пшеница) необходимо рассматривать отраженный свет этих двух видов.

Модели, которые допускают, что листья являются диффузными отражателями, правильно прогнозируют только долю диффузного отражения растительности. Но одно это не предоставляет возможности достаточно точно прогнозировать коэффициент отражения растительности. Такие модели нельзя будет использовать для определенной комбинации углов обзора изучаемых образцов растительного покрова, поскольку они не описывают фактическое соотношение между причиной и результатом влияния излучения. Исследованное состояние для оценки посевов пшеницы в Шекинском районе Азербайджанской Республики зеркальное отражение показано как ключевой аспект изучения радиационного переноса и измерения поляризации света, проведенный для определения зеркального и диффузного отражения излучения от растительности.

В работе показана важность и реальная возможность использования спутниковых бортовых датчиков для получения информации в диффузно отраженном излучении рассматриваемой растительности, а дополнительно осуществляемые наземные измерения поляризации послужат для разработки улучшенных моделей радиационного переноса в растениях. 


\section{Список литературы}

[1] Мехтиев В.Ш., Азизов Б.М., Бадалова А.Н. // Вестн. Азербайджанской инженерной академии. 2014. Т. 6. № 4. C. $120-130$.

[2] Мехтиев А.Ш., Азизов Б.М., Мехтиев Д.С. // Сборник материалов научно-технической конференции „Средства и технологии ДЗЗ из космоса“. СПб, 2014. С. 8-15.

[3] Азизов Б.М., Мехтиев Д.С., Кулиева С.Г. // Сборник материалов конференции „Современные проблемы ДЗЗ из космоса“. 2017. С. 346.

[4] Гулиев Р.Б., Азизов Б.М., Аббасзаде А.А. // Опт. и спектр. 2009. T. 106. № 1. C. 514-517.

[5] Сидько А.Ф., Ботвич И.Ю., Листан Т.И. // Исследование Земли из космоса. 2013. № 2. С. 3-12.

[6] Gitelson A.A., Vin A.A., Rundqust D.S., Arnebauer T.S. // Geophys. Res. Lett. 2005. V. 32. N 108403. doi:10.1029/2005 GLO 022688

[7] Suomalainen J., Havala T., Pattonen E., Peltoniemi J. // J. Quantitat. Spectrosc. Radiat. Transfer. 2009. V. 110. P. 1044-1056.

[8] Zhongqlu Sun, Di Wu, Yunsheng Z. // J. Geophysical Research Atmospheres. 2017. P. 1042-1065.

[9] Vanderbilt V.C., Grant T.L., Daughtru C.S. // ТИИЭР. 1985. T. 73. N 6. C. $72-85$. 